\title{
Sonic log simulations in wells of Campos and Santos Basins using Gardner, multiple linear regression, geological differential method and artificial intelligence approaches
}

\author{
Lucas Carvalho ${ }^{1}$ and Abel Carrasquilla ${ }^{1}$
}

\begin{abstract}
1Petroleum Engineering and Exploration Laboratory, Darcy Ribeir
Highway, Brennand Avenue S/N, Imboassica, Macae-RJ, 27930-480.
Copyright 2019, SBGf - Sociedade Brasileira de Geofísica

This paper was prepared for presentation during the $16^{\text {th }}$ International Congress of the Brazilian Geophysical Society held in Rio de Janeiro, Brazil, 19-22 August 2019.

Contents of this paper were reviewed by the Technical Committee of the $16^{\text {th }}$ International Congress of the Brazilian Geophysical Society and do not necessarily represent any position of the SBGf, its officers or members. Electronic reproduction or storage of any part of this paper for commercial purposes without the written consent of the Brazilian Geophysical Society is prohibited.
\end{abstract}

\begin{abstract}
The sonic log sometimes is not collected in many wells, but its lack can be overcome by the synthesis, associating it to gamma rays, resistivity, density and neutron porosity logs. One of the most used models to do this was developed by Gardner et al. (1974), who relates the compressional wave velocity to the density, but not always obtaining satisfactory results. As an alternative, several studies correlate the speed of the compression waves with other basic logs, applying approaches such as neural networks, fuzzy logic and multiple linear regression. Thus, the objective of this work was to simulate the compressional wave velocity using the Gardner model and compare the results with the abovementioned techniques together with the geological differential method. For this purpose, 57 wells from the Campos and Santos Basins were used which have siliciclastic and carbonate reservoirs in the post and presalt layers. The obtained results showed that, excepting the fuzzy logic and neural network approaches, all the other techniques are efficient. The Gardner model proved to be efficient even when using only the density log to simulate the compression wave velocity. The multiple linear regression and the geological differential method obtained better results in areas of high porosity, since they use the gamma and resistivity logs, which record better the effects of the fluids.
\end{abstract}

\section{Introduction}

One of most important tools in oil exploration is the well logging, because it provides an estimate of the petrophysical properties and, a reliable calculation of the volumes of oil and water in the reservoirs. Basic suite of logs as gamma ray (GR), resistivity $(R T)$, density (RHOB), neutron (NPHI) and sonic (DT) are used for this purpose.

A major contribution to seismic is the DT log, since it provides important estimates of the physical properties of perforated rocks, such as the interpretation of the lithology, the determination of geopressions, the identification of fractures and the inversion of seismic attributes. However, this log had for a long time as the main function to determine the porosity and, occupy the spaces where this property does not exist for the $\mathrm{RHOB}$ and NPHI logs and, more recently, for the nuclear magnetic resonance log (Augusto \& Martins, 2009; Islam, 2011).

Despite this importance, often this log is not available in many wells, due to data loss in old wells, technical failures during its acquisition or by, simply, economic option (Leite, 2007). The missing log can be simulated from rock physics models, petrophysical properties of samples and, RHOB and RT logs (Cao et al., 2017). But, not always with satisfactory results. Gardner et al. (1974) developed an important model for predicting DT log using the correlation between the $\mathrm{RHOB}$ and the compressional wave velocity $\left(V_{P}=1 / D T\right)$ logs. Another well-known work was done by Faust (1953), who used a new lithologic parameter derived from the RT log.

Currently, several studies have been carried out using multiple linear regression (MLR), fuzzy logic (FL) and neural networks (NN). Alongside these techniques, we also used the geological differential method (GDM). One fact that stands out in these studies is that in most of them a few wells were used and low complexity rocks to characterize the reservoirs (Tischler et al., 2006). This creates a stimulus, as made in this work, to apply these techniques in a big dataset and in all the well extension, which characterize a common situation in the oil industry (Hurst et al., 2009).

\section{Method}

In this work, Interactive Petrophysics (IP) software (LR Senergy, 2012) was used for all data manipulation, including loading and plotting of logs, selection of wells to be used, simulation of logs and creation of graphs with results. These results were exported to Microsoft Excel where statistical analyzes were performed. For this work, 133 wells from 6 different oil fields were made available, 4 of which cross the post-salt of the Campos Basin (130 wells) and 2 fields the Santos Basin pre-salt ( 3 wells). Of the 133 wells available, 57 were selected because they presented the basic set of logs (GR, RT, RHOB, NPHI and DT) in good conditions, being 3 pre-salt wells and 54 post-salt wells. After that, Gardner (GM), multiple linear regression (MLR), fuzzy logic (FL), neural networks (NN) and geological differential (GDM) methods were used to estimate the compressional wave velocity ( $V_{P}$ _SIMULATED). The quality of the estimate was then tested according to the quality of the fit with $V_{P}$ real $\log$ ( $V_{P}$ LOG), using statistical parameters such as Pearson's correlation $(R)$ and determination $\left(R^{2}\right)$ coefficients and, the root means 
square error (RMSE). The article follows the workflow of Figure 1.

\section{Results}

The results for post-salt wells are shown in Figures 2, 3 and 4 , where the tracks, from left to right, show: depth (track 1), lithological classification (siliciclastic and carbonate reservoirs, track 2), GR and $V_{P}$ logs (track 3), RHOB and NPHI logs (track 4) and RT log (track 5). Subsequently, $V_{P}$ LOG (light blue) and $V_{P}$ SIMULATED, for different methods in all the 57 wells, were plotted in this way in green: $V_{P_{-} G M}$ (track 6), V $V_{\text {P_MLR }}$ (general model,

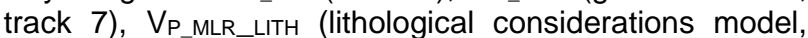
track 8), VP_GDM (general model, track 9), V $P_{\text {P_GDM_LITH }}$ (lithological considerations, track 10), $V_{P}$ NN (track 11) and $V_{P_{-} F L}$ (track 12) models. The studied part in post-salt wells is shown in the red rectangle while the entire range was analyzed in pre-salt wells. On the other hand, Tables 1 and 2 show the equations of the lines adjusted in the graphs of $V_{P_{-} L O G}$ versus all other estimates (VP_GM,

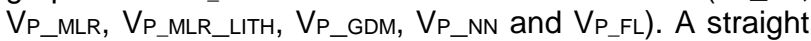
line, with a slope of $45^{\circ}$, was also plotted to compare its similarity with the best fit line (Figure 5). For the statistical analyzes, Tables 2 and 3 shows, respectively, Pearson's correlation $(R)$ and determination $\left(R^{2}\right)$ coefficients, while Table 4 presents the root mean square error (RMSE).

The linear equations of the adjustment of $V_{P}$ SIMULATED to $V_{P_{-} \text {LOG }}$ is shown in Table 1 for all wells. Figures 2, 3 and 4 analyze the post-salt wells, where $V_{P_{-} N N}$ and $V_{P_{-} F L}$ estimates have low variations (tracks 11 and 12). They have a good approach to $V_{P \_L O G}$ but do not represent well the lithology. On the other hand, $V_{P_{-} M L R}, V_{P_{A} G D M}$ and $V_{P}$ GM estimates present good fit but, they disagree with $V_{\text {P_LOG }}$ at some intervals (tracks 6 to 10). In general, it can be observed that the $V_{P}$ MLR and $V_{P}$ GDM had the best results, in both Pearson coefficients $\left(R\right.$ and $\left.R^{2}\right)$, in RMSE values (Tables 3,4 e 5 ), as well as the slope of the adjustment line, which approximate of $45^{\circ}$ (Figure 5 ). The values of $R^{2}$ and RMSE for $V_{P} F L$ are better than $V_{P} G M$ but, they are not considered good because $V_{P_{-} G M}$ is closer to straight with $45^{\circ}$ (Figure 5). This can be explained by the fact that the simulation by $V_{P}$ FL arrived at an estimate with low variability, always obtaining values close to $V_{P_{-} L O G}$, but not with the variations caused by the lithology. The models $V_{P_{N N}}$ and $V_{P_{F}}$ have better estimates with siliciclastic and carbonate rocks are separated. They show an increase in $\mathrm{R}^{2}$, a RMSE reduction and an approximation to straight of $45^{\circ}$. Whereas the methodology for separating these lithologies is simple and can be improved, the results can still be best.

Figures 6,7 and 8 present $V_{P_{\text {SSIMULATED }}}$ logs for the 3 presalt wells, which served as a blind test, that is, they were not used in the construction of the models (tracks 6 to 12). Table 5 shows the relationship between $V_{P_{-} \text {SIMULATED }}$ and $V_{P}$ LOG for the 3 wells of the pre-salt with the corresponding equations. Analyzing the logs of the 3 wells, we can notice different characteristics of the PreSalt Well 1 in relation to the Pre-Salt Wells 2 and 3 , which can be explained by the fact that the Well 1 is in a different oilfield from Wells 2 and 3 , which are from the same field. Well 1 shows high GR log values for carbonates which are like siliciclastic rocks, what may cause differences in the simulations in this borehole. The estimate for $\mathrm{V}_{\mathrm{P} F \mathrm{~F}}$ in pre-salt displays worse results than the post-salt wells, as shown in Figure 7 (track 11) and Table 4. The simulation of $V_{P \_N N}$, obtained good results in terms of values of $R^{2}$ and RMSE, it is observed that the adjustment line is very distant from the ideal slope of $45^{\circ}$ (Figure 9). Like what was observed in the general analysis ( 57 wells) for the simulation of $V_{P_{F} F_{L}}$ and $V_{P_{P} N N}$, this can be explained by their small variability.

Analyzing the logs plotted in Figures 6, 7 and 8, the graphs of Figure 9 and their respective values of $R^{2}$ in Table 3, in addition to the RMSE values in Table 4, it can

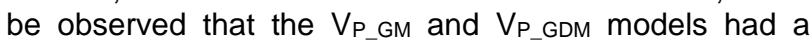
good correlation with $V_{P} \_$LOG. As observed before, pre-salt Well 1 has different geological characteristics and, therefore, none of the models obtained satisfactory $R^{2}$ when the well was analyzed alone. In addition, when analyzing the plotted logs, we can observe a great similarity with $V_{P \_L O G}$, especially those of $V_{P}$ GDM and $V_{P \text { NN. }}$. By considering only the wells 2 and 3 , the $V_{P}$ GM obtains higher values of $\mathrm{R}^{2}$, in addition to approaching the real log when plotted. However, it is observed that the $V_{P}$ GDM method presents slope of the adjustment line very close to $45^{\circ}$ (Figure 9), and still obtained a lower RMSE value, being considered the best method of prediction in the 3 wells of the blind test. Unlike the general analysis, the application of siliciclastic and carbonate rocks separation in the VP_MLR and VP_GDM models did not show a substantial improvement in the results.

\section{Conclusions}

The Gardner model produces good results in the simulation of compressional wave velocity in post and pre-salt wells in Campos and Santos Basins. They have, although, a low correlation with the real log in areas with many fluids, which are caused by the presence of shale and/or high porosity. This effect was not observed in other models, since they use density, gamma rays and resistivity logs in the simulation, which show a greater sensitivity to the presence of fluids. The fuzzy logic and neural network models did not have good results, although in some cases the comparison with the real log, they show similar or better values of Pearson coefficient of determination and root mean square error than the other methods. The simulated curves for neural network and fuzzy logic show few changes, which shows that they are not good for recording lithological changes. In a general analysis, all 57 wells used in the study (54 model wells and 3 blind wells), the multiple linear regression proved to be the most efficient, followed by the geological differential method. There is also a slight improvement in the correlations for these models when they are simulated using the separation between siliciclastic and carbonate rocks. When analyzing only the 3 pre-salt wells of the Santos Basin (blind test), the geological differential method model obtained the best results, followed by the Gardner and multiple linear regression. In the Pre-salt Well 1, none of the methods presented satisfactory Pearson coefficient of determination. The neural network and the geological differential method show a low root mean square error when plotted together with real log. Possibly, this result is caused by the high values of 
gamma ray log above the carbonate reservoir. Essentially, the geological differential method presented the best results, followed by the Gardner and multiple linear regression methods. The three methods demonstrated the ability to simulate the sonic log when it is not available, and Gardner has the advantage of using only the density log, while the others require that the gamma ray and resistivity logs are also available.

\section{Acknowledgments}

We thank Petrobras and Petrogal Brasil S.A. by the support to develop this study, CNPq for the research grant and UENF-LENEP for their physical and computational infrastructure.

\section{References}

Augusto, F. and Martins, J. 2009. A well-log regression analysis for $p$-wave velocity prediction in the Namorado Oilfield, Campos Basin. Brazilian Journal of Geophysics, Scielo, v. 27, n. 4, p. 595-608, 2009.

Cao, J.; Shi, Y.; Wang, D. and Zhang, X. 2017. Acoustic log prediction based on kernel extreme learning machine for wells in GJH survey, Erdos Basin. Hindawi, Volume 2017, Article ID 3824086, 7 p. velocity function including lithologic variation. Geophysics, SEG, v. 18, n. 2, p. 271-288.

Gardner, G.; Gardner, L. and Gregory, A. 1974. Formation velocity and density - the diagnostic basics for stratigraphic traps. Geophysics, SEG, v. 39, n. 6, p. 770780 .

Hurst, A. and Tischler, G. 2009. Predicting reservoir characteristics from drilling and hydrocarbon-gas data using advanced computational mathematics. SPE Offshore Europe Oil \& Gas Conference \& Exhibition, Aberdeen, UK, SPE 123785.

Islam, N. 2011. Sonic log prediction in carbonates. Master's Thesis, Michigan Technological University, 92 p.

Leite, M. 2007. Simulation of the sonic log for wells in the Namorado Oilfield using fuzzy logic. Master's Thesis, UENF, Macaé - RJ, 165 p. (In Portuguese).

LR Senergy. 2012. Interactive Petrophysics User's Manual.

Tischler, G.; Arkalgud, R. and Hurst, A. 2006. Prediction of petrophysical characteristics from borehole gas and drilling data. 68th EAGE Conference and Exhibition and SPE Europec: Opportunities in Mature Areas, Vienna, Austria.
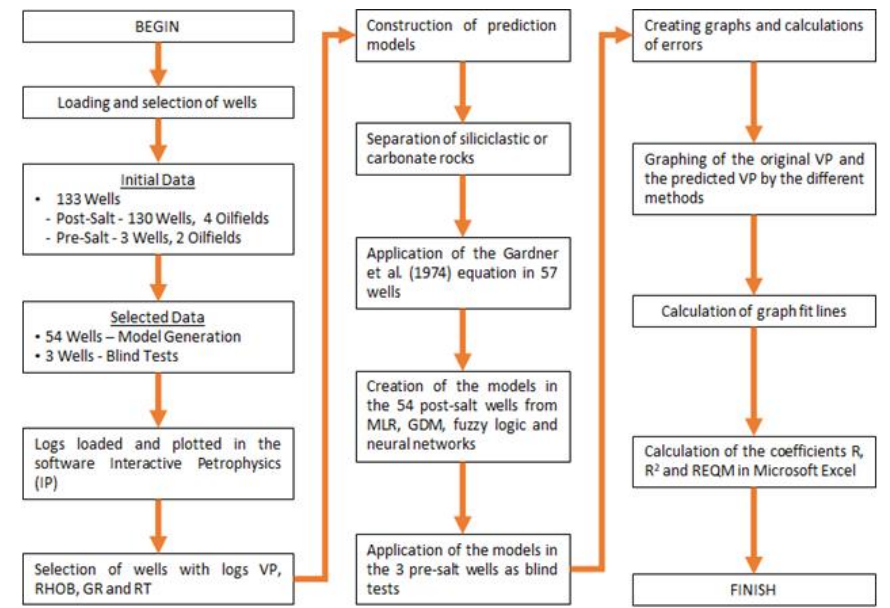

Figure 1. Workflow of this article.

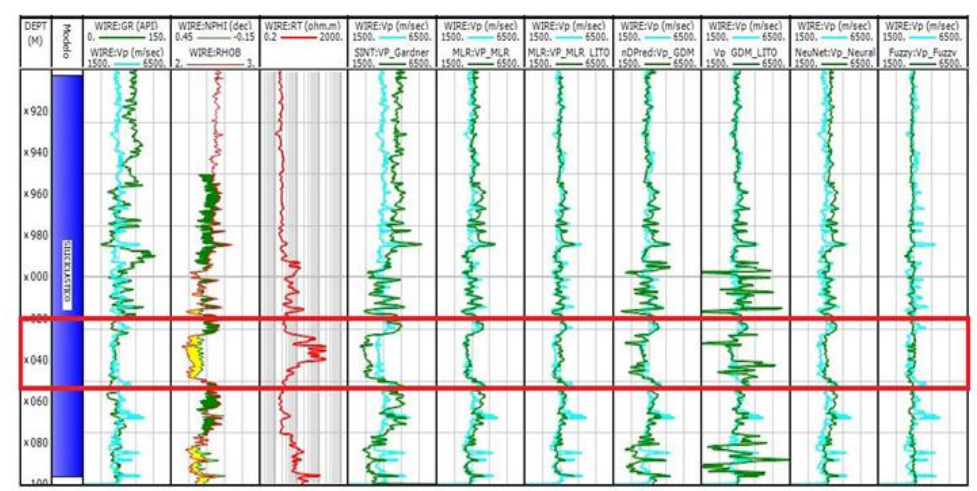

Faust, L.

1953. A 


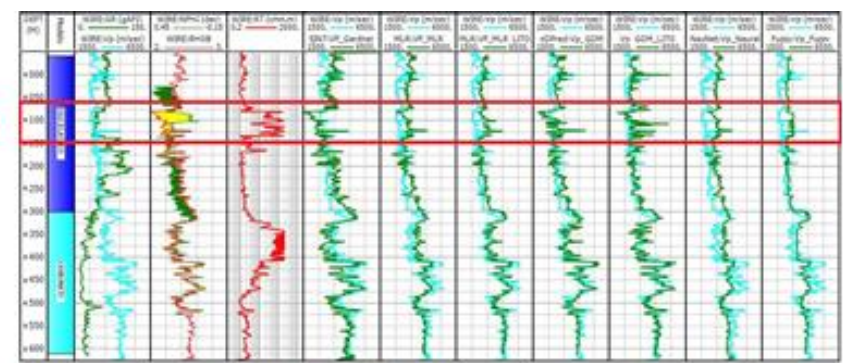

Figure 3. Simulated logs in one of the Campos Basin post-salt wells used for model construction. The highlighted region shows the effects of the presence of gas in the siliciclastic reservoir.

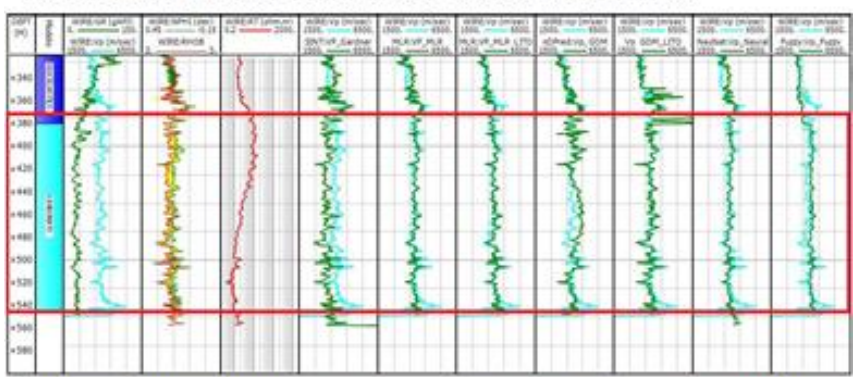

Figure 4. Simulated logs in one of the Campos Basin post-salt wells used for model construction. The highlighted region shows the effects of fluid in a carbonate reservoir in the simulation of the logs.

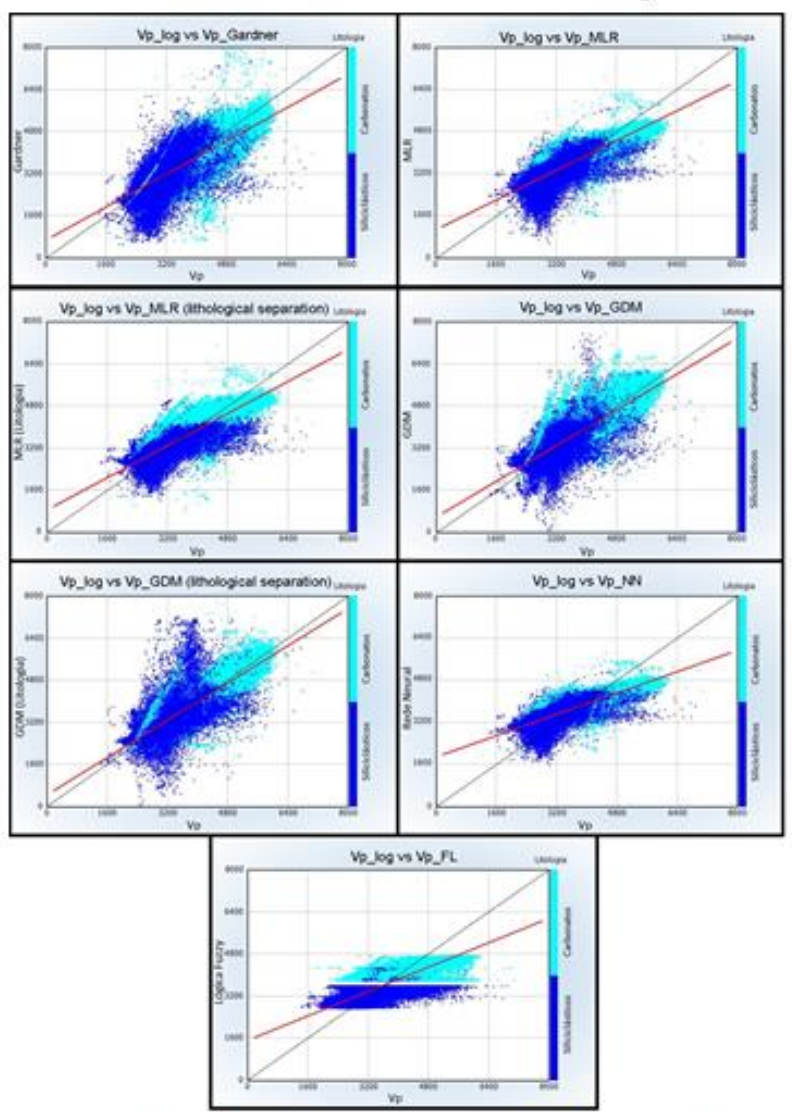

Figure 5. Graphs of $V_{p \text { LOG }}$ versus $V_{p \text { SIMULATED }}$ in all 57 wells used with the curve-fitting line, whose equations are in Table 1 , while $\mathrm{R}^{2}$ are in Table 3 . The data were separated according to lithology in siliciclastic (dark blue) and carbonate (light blue) rocks. 


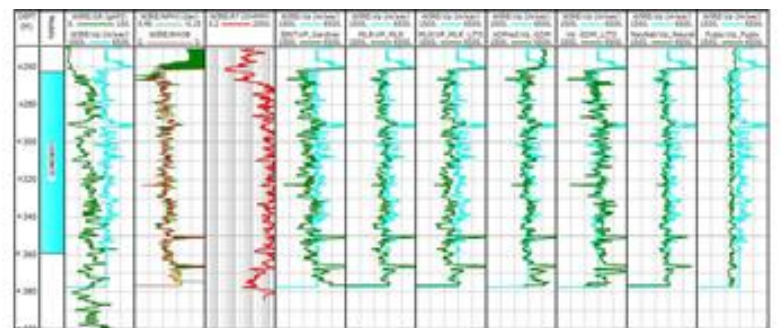

Figure 6. Simulated curves for Well 1 of the Santos Basin pre-salt.

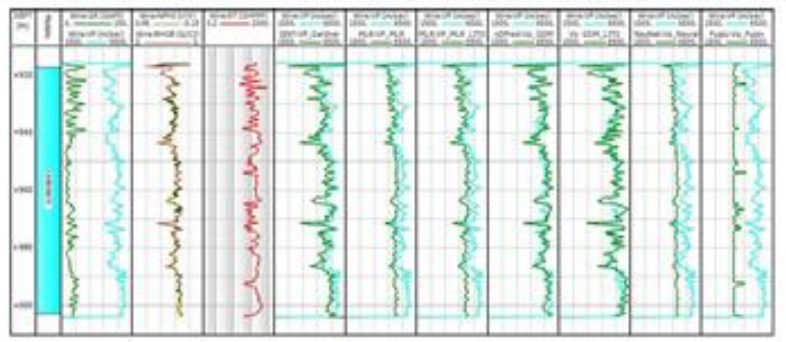

Figure 7. Simulated curves for Well 2 of the Santos Basin pre-salt.

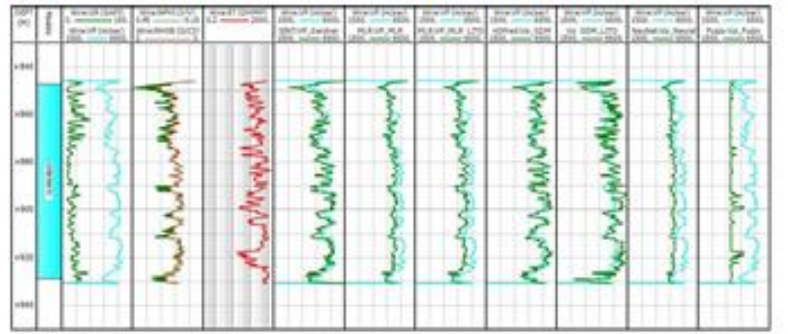

Figure 8. Simulated curves for Well 3 of the Santos Basin pre-salt.

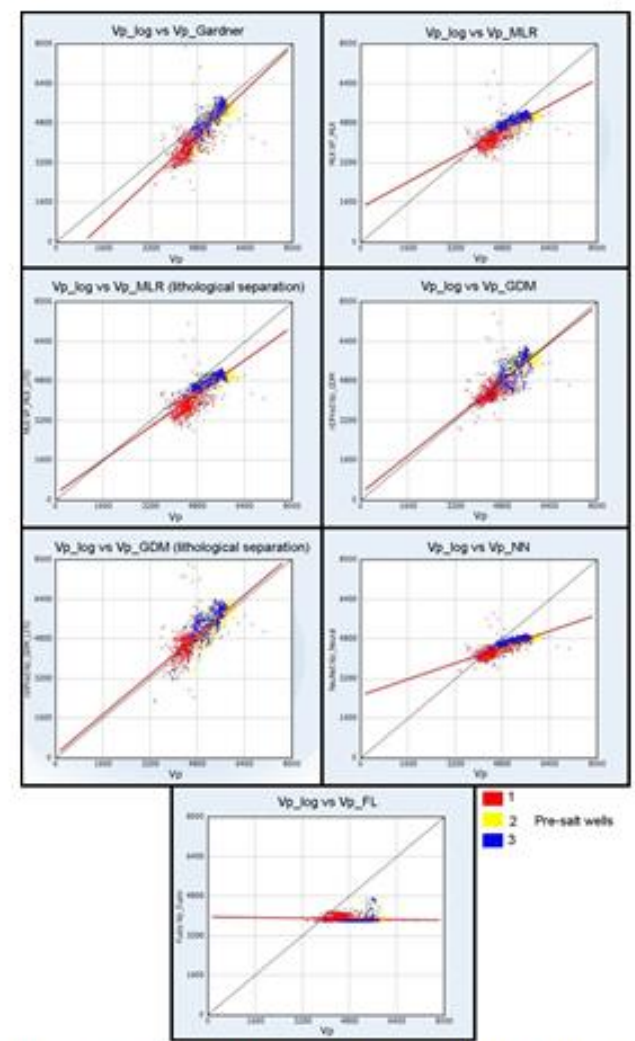

Figure 9. Graphs of Vp_log versus Vp_simulated in wells 1,2 and 3 of the pre-salt. The equations of the straight lines of adjustment are given in Table 5, while $\mathrm{R}^{2}$ are shown in Table 3. 
Table 1. Linear adjusted equations of Vp_log versus Vp_simulated (Gardner, MLR, MLR (lithology), GDM, GDM (lithoiloy), NN and FL) in all the used 57 wells.

\begin{tabular}{|l|c|}
\hline Gardner & Vp-Gardner $=656.684+0.78762 \mathrm{Vp}$ \\
\hline MLR & Vp-MLR $=1061.54+0.706433 \mathrm{Vp}$ \\
\hline MLR (lithology) & Vp-MLR(Lito) $=858.997+0.761371 \mathrm{Vp}$ \\
\hline GDM & $\mathrm{Vp}-\mathrm{GDM}=581.868+0.849778 \mathrm{Vp}$ \\
\hline GDM (lithology) & $\mathrm{Vp}-\mathrm{GDM}($ Lito $)=453.281+0.884034 \mathrm{Vp}$ \\
\hline NN & Vp-Neural $=1887.43+0.506964 \mathrm{Vp}$ \\
\hline FL & Vp-Fuzzy $=1506.96+0.580693 \mathrm{Vp}$ \\
\hline
\end{tabular}

Table 2. Pearson's correlation coefficients (R).

\begin{tabular}{|c|c|c|c|c|c|c|c|}
\hline Wells & Gardner & MLR & \begin{tabular}{c|c}
$M L R$ \\
(Lithology)
\end{tabular} & GDM & \begin{tabular}{|c|} 
GDM \\
(Lithology) \\
\end{tabular} & $\begin{array}{c}\text { Neural } \\
\text { Network }\end{array}$ & $\begin{array}{l}\text { Fuzzy } \\
\text { Logic }\end{array}$ \\
\hline 57 (total) & 0.74 & 0.85 & 0.88 & 0.84 & 0.86 & 0.71 & 0.83 \\
\hline 3 wells Pre-salt & 0.77 & 0.79 & 0.80 & 0.80 & 0.77 & 0.80 & -0.06 \\
\hline Well 1 Pre-salt & 0.34 & 0.45 & 0.42 & 0.45 & 0.48 & 0.49 & -0.06 \\
\hline $\begin{array}{c}\text { Well } 2 \text { and } 3 \\
\text { Pre-salt }\end{array}$ & 0.82 & 0.73 & 0.76 & 0.71 & 0.72 & 0.74 & 0.19 \\
\hline Well 2 Pre-salt & 0.81 & 0.67 & 0.69 & 0.72 & 0.75 & 0.70 & 0.11 \\
\hline Well 3 Pre-salt & 0.86 & 0.80 & 0.82 & 0.69 & 0.72 & 0.79 & 0.30 \\
\hline
\end{tabular}

Table 3. Pearson's determination coefficients $\left(R^{2}\right)$.

\begin{tabular}{|c|c|c|c|c|c|c|c|}
\hline Wells & Gardner & MLR & \begin{tabular}{c|c}
$M L R$ \\
(Lithology) \\
\end{tabular} & GDM & \begin{tabular}{|c|} 
GDM \\
(Lithology)
\end{tabular} & $\begin{array}{c}\text { Neural } \\
\text { Network }\end{array}$ & $\begin{array}{l}\text { Fuzzy } \\
\text { Logic }\end{array}$ \\
\hline 57 (total) & 0.55 & 0.72 & 0.77 & 0.71 & 0.73 & 0.51 & 0.69 \\
\hline 3 wells Pre-salt & 0.59 & 0.63 & 0.64 & 0.64 & 0.60 & 0.64 & 0.004 \\
\hline Well 1 Presalt & 0.12 & 0.20 & 0.18 & 0.21 & 0.24 & 0.24 & 0.004 \\
\hline $\begin{array}{l}\text { Welli2 and } 3 \\
\text { Pre-salt }\end{array}$ & 0.68 & 0.53 & 0.58 & 0.51 & 0.51 & 0.54 & 0.04 \\
\hline Well 2 Pre-salt & 0.65 & 0.45 & 0.47 & 0.52 & 0.57 & 0.49 & 0.01 \\
\hline Well 3 Pre-salt & 0.74 & 0.63 & 0.67 & 0.48 & 0.52 & 0.63 & 0.09 \\
\hline
\end{tabular}

Table 4. Root Mean Square Error (RMSE).

\begin{tabular}{|c|c|c|c|c|c|c|c|}
\hline Wells & Gardner & MLR & \begin{tabular}{|c|} 
MLR \\
(Lithology)
\end{tabular} & GDM & \begin{tabular}{|c|} 
GDM \\
(Lithology)
\end{tabular} & $\begin{array}{c}\text { Neural } \\
\text { Network }\end{array}$ & $\begin{array}{l}\text { Fuzzy } \\
\text { Logic }\end{array}$ \\
\hline 57 (total) & 594.6 & 416.0 & 376.2 & 448.9 & 429.4 & 578.1 & 453.1 \\
\hline 3 wells Pre-salt & 678.8 & 494.3 & 653.7 & 390.6 & 479.4 & 573.5 & 1242.3 \\
\hline Well 1 Pre salt & 946.9 & 522.6 & 801.5 & 449.5 & 530.4 & 421.1 & 724.1 \\
\hline $\begin{array}{l}\text { Welli2 and } 3 \\
\text { Pre-salt }\end{array}$ & 442.5 & 476.2 & 544.7 & 349.9 & 445.6 & 648.9 & 1470.6 \\
\hline Well 2 Pre-salt & 480.7 & 545.3 & 603.3 & 302.6 & 400.1 & 727.8 & 1571.7 \\
\hline Well 3 Pre-salt & 398.6 & 391.2 & 475.6 & 393.4 & 488.7 & 554.3 & 1356.8 \\
\hline
\end{tabular}

Table 5. Equations of the adjustment lines of Vp_log versus Vp_simulated graphs in the pre-salt wells shown in Figure 7.

\begin{tabular}{|l|c|}
\hline Gardner & Vp-Gardner $=-1033.84+1.12025 \mathrm{Vp}$ \\
\hline MLR & $\mathrm{Vp}-\mathrm{MLR}=1376.77+0.650739 \mathrm{Vp}$ \\
\hline MLR (lithology) & $\mathrm{Vp}-\mathrm{MLR}(\mathrm{Lito})=236.833+0.842593 \mathrm{Vp}$ \\
\hline GDM & $\mathrm{Vp}-\mathrm{GDM}=249.421+0.948353 \mathrm{Vp}$ \\
\hline GDM (lithology) & $\mathrm{Vp}-\mathrm{GDM}(\mathrm{Lito})=124.128+1.00591 \mathrm{Vp}$ \\
\hline NN & $\mathrm{Vp}-$ Neural $=2525.17+0.404884 \mathrm{Vp}$ \\
\hline FL & Vp-Fuzzy $=3968.34-0.0172339 \mathrm{Vp}$ \\
\hline
\end{tabular}

